Summit Strategies: Secrets to Mastering the Everest in Your Life

Gary P. Scott

Hillsboro, OR: Beyond Words Publishing, Inc, 2003

US \$13.95, 128 pages, softcover

David Breashears said of this book "We all have an Everest to climb and master in our lives. This book gives the steps to take to help you overcome your doubts and fears and move closer to your dreams."

Gary Scott is an accomplished mountaineer and guide who has compiled hard-learned lessons from his climbing career into 10 pearls of wisdom that apply to everyday life. The lessons, laid out in 10 chapters, tell stories from expeditions that teach a valuable principle that the author goes on to translate into routine situations of daily life. "Choose Your Mountain" (identify your goal), "Lighten Your Load" (remove the clutter from your life), and "Find Your Pace" (determine a timeframe in which to reach your goals) are just 3 of the 10 enlightening chapters.

The theories in these lessons will teach nothing new to anyone who spends much time in the self-help section of their bookstore. But for mountaineers who don't count Deepak Chopra among their favorite authors, Scott's approach to life strategizing may be refreshing (and familiarly illustrated). Kind of like "Dr Phil goes to the mountains."

On a personal note, I had the opportunity to befriend Gary at Mt Everest during his second summit attempt in 2003. It was an unsuccessful and tragic bid for Scott. As I watched him endure serious personal illness and the death of his friend and climbing Sherpa, Karma, I was impressed by Gary's extraordinary character and ability to think outside his own personal discomfort and misfortune. He doesn't just talk the talk, he really does walk the walk.

This book will appeal to anyone interested in personal growth, from a mountaineer preparing for a challenging expedition to a college student preparing for a job interview. It's an easy, quick read and a good pep talk for anyone facing life's challenges.

Luanne Freer, MD

Bozeman, MT, USA

\section{Birding on Borrowed Time}

Phoebe Snetsinger

Colorado Springs, CO: American Birding Association, 2003

US \$19.85, 307 pages, 45 illustrations, softcover

Phoebe Snetsinger was perhaps the most obsessive birdwatcher of modern times. During a lifetime of birding she saw - and clearly identified-more than 8000 species around the world. She did not come to birding early in life and was 34 when she suddenly recognized the beauty and incredible variety of bird species waiting to be seen. However, once she had become enthusiastic, there was no stopping her.

Birding is usually thought of as a safe, benign hobby for people not interested in wilder, more dangerous sports, but during her experiences as a world traveler and adventurer, Phoebe Snetsinger faced many emergencies. The first emergency was the diagnosis in 1972 of a malignant melanoma in the middle of her back. As the years passed by, she had several recurrences, but this never diminished her determination to see as many species as possible. After her personal discovery of the third recurrence she decided not to tell anyone, including her husband, and went on a birding trip to Australia, thinking that she probably had metastases throughout her body. On her return, she told her doctor about the discovery that the lesion had grown in the weeks she had been away, but that she had decided to go on the trip, no matter what the outcome. To her surprise and pleasure, her doctor listened to her story and said, "I think that, under the circumstances, I would have done the same." She says in the book that she could have kissed him.

She survived an earthquake in Costa Rica, and, with her husband, was attacked by a gang in New Guinea. She was taken into the forest and gang-raped by 5 men. When the gang had disappeared, she and her husband had a harrowing escape to a friendly village.

Incidents of this sort did not slow down her enthusiasm and determination. Ironically, after surviving malignant melanoma and vicious attacks, she was killed in a van accident in Madagascar while napping on a back seat.

Phoebe designed a bird classification system for keeping records of her own. (Examples of her handwritten notes are in the book.) She also held a strong view that hearing a bird was not sufficient. In order to add the bird to your life list, you must see it and identify it clearly.

If this book had been a graphic account of her travels and adventures - and there were plenty of both-it would appeal to the ordinary reader, but the frequent accounting of exotic birds seen detracts from the readability of the book, for example, "Offsetting such major and minor problems, we found a staggering number of really special birds, such as the Thick-billed Cuckoo, Boehm's Bee-eater, Pale-Billed Hornbill, Blue swallow, Bocage's and Sharpe's Kalatas, Fuellborn's Longclaw, Souza's Shrike, Anchieta's Sunbird, Bar-winged Weaver and Locustfinch." Balanced against this disadvantage are the beautiful pencil illustrations of many of the spe- 
cies mentioned, drawn by the well-known bird illustrator H. Douglas Pratt.

This is definitely a book for the birding aficionado. For anyone aspiring to increase their life-list into the thousands of species and wondering where to go and how to do this, this book should inspire them-even if their bank balance may not allow them to imitate her classic journeys.

Bruce C. Paton, MD

Denver, CO, USA

\section{Exotic Viral Diseases: A Global Guide}

Stephen A. Berger, Charles H. Calisher, and Jay S. Keystone

Hamilton, Ontario, Canada: BC Decker Inc, 2003

US \$29.95, 252 pages, softcover

Infectious disease is a rapidly evolving field; new viral agents are continually being identified, and the geographic ranges of known viruses continue to evolve. As recent experiences with West Nile virus, severe acute respiratory syndrome (SARS), and monkeypox dramatically illustrate, clinicians in any setting may be called on to consider infectious entities from any part of the globe due to shifts in geographic disease distribution, travel-related imported infections, or even potentially intentional releases of exotic viruses.

Exotic Viral Diseases: A Global Guide provides a valuable source of information about some well-known and many obscure viruses. It does this within the confines of a pocket-sized book and a CD-ROM. In no other book of this size can one read about Ilhéus and Bussuquara fevers (causes of fever, myalgias, and occasionally encephalitis in Brazil, Columbia, and Panama), O'nyong-nyong fever (a mosquito-borne togavirus infection that causes fever, headache, conjunctivitis, and arthralgias and that has caused massive outbreaks in central Africa), or Kyasanur Forest disease (which has caused outbreaks of fever, conjunctivitis, and often hemorrhagic pulmonary edema in India), not to mention many others such as tanapox virus, Thogoto virus, and Sindbis fever.

The introduction contains some useful discussion of the general approach to exotic viruses, which are defined as viruses of either limited geographic distribution or ones that are rarely encountered. There are some useful tables categorizing the exotic viruses by their vectors, routes of transmission, and natural reservoirs. Other tables list the viral agents that may cause conjunctivitis, encephalitis, or other clinical presentations.

The bulk of the book consists of concise descriptions of the specific exotic viruses, including the frequent numerous synonymous names for the viruses, their reservoirs, vectors, mode of transmission, incubation periods, clinical presentation, appropriate diagnostic tests, therapy, geographic range, and relevant isolation precautions. These sections are very clear and to the point.

The entry for each virus also includes a brief but helpful list of additional references. These citations are particularly valuable because searching for additional references on viruses as obscure as some of these can be difficult with ordinary medical on-line literature; these viruses frequently do not have their own search terms. For example, an attempt to search a common on-line medical literature search system for references on Rocio virus (an uncommon cause of viral illness in rural Brazil, which may progress to encephalitis with a $10 \%$ mortality) refers one to thousands of articles on the entire family of flaviviruses, while the section in Exotic Viral Diseases on Rocio encephalitis provides a concise description and 4 references.

Since infectious disease is such a rapidly changing field, it is impossible for any text to remain current for long. This book is a good example, since it was published before the SARS epidemic and does not refer to the SARS coronavirus, and while it does contain a section on monkeypox, it does not mention the use of smallpox vaccine for the pre-exposure or postexposure management of monkeypox. The section on Japanese encephalitis would also be enhanced by a table or listing of the seasons of risk in the involved countries. Overall, these are minor and understandable limitations.

Exotic Viral Infections comes with a handy CD-ROM. While the CD contains the complete text of the book in the exact same format, the $\mathrm{CD}$ is more easily searched and therefore is in some ways more user-friendly than the actual text. The text is organized according to specific viral diseases. Consequently, to identify the viral infections prevalent in a specific country in the hardcopy of the book requires a certain amount of flipping around, while with the CD-ROM, merely clicking on edit, search, and query quickly pulls up all the viruses prevalent in that country.

The complete focus on viral infections, including many not often considered, is the strength of this book. It is also its most significant limitation. Clinicians seeking information on the range of infections prevalent in particular regions of the world, or seeking differential diagnostic possibilities for patients with specific constellations of symptoms, will be well alerted to a comprehensive range of possible viral etiologies, but only viral possibilities, as bacterial, fungal, parasitic, and noninfectious entities are not within the scope of the book. The book will be most useful when used as an adjunct 